\title{
Arteriovenous Graft Placement in Predialysis Patients: A Potential Catheter-Sparing Strategy
}

\author{
Roman Shingarev, MD ${ }^{\mathrm{a}}$, Ivan D. Maya, MD ${ }^{\mathrm{a}}$, Jill Barker-Finkel, PhD $^{\mathrm{b}}$, and Michael Allon, \\ $M^{\mathrm{a}}$ \\ aDivision of Nephrology, University of Alabama at Birmingham, Birmingham, Alabama \\ bepartment of Microbiology, Montana State University, Bozeman, Montana
}

\begin{abstract}
Background-When pre-dialysis patients are deemed to be unsuitable candidates for an arteriovenous fistula, current guidelines recommend waiting until just before or after initiation of dialysis before placing a graft. This strategy may increase catheter use when these patients start dialysis. We compared the outcomes of patients whose grafts were placed before and after dialysis initiation.
\end{abstract}

Study design-Retrospective analysis of a prospective computerized vascular access database.

Setting and participants-Chronic kidney disease patients receiving their first arteriovenous graft $(n=248)$ at a large medical center.

Predictor-Timing of graft placement (before or after initiation of dialysis)

Outcome \& measurements-Primary graft failure, cumulative graft survival, catheterdependence, and catheter-related bacteremia.

Results-The first graft was placed pre-dialysis in 62 patients and post-dialysis in 186 patients. Primary graft failure was similar for pre-dialysis and post-dialysis grafts ( $20 \mathrm{vs} 24 \%$; $\mathrm{p}=0.5$ ). The median cumulative graft survival was similar for the pre-dialysis and post-dialysis grafts (365 vs 414 days; HR, 1.22; 95\% CI, 0.81-1.98; $\mathrm{p}=0.3$ ). The median duration of catheter-dependence after graft placement in the post-dialysis group was 48 days, and was associated with 0.63 (95\% CI, $0.48-0.79)$ episodes of catheter-related bacteremia per patient.

Limitations-Retrospective analysis, single medical center

Conclusion-Grafts placed pre-dialysis have similar primary failure rates and cumulative survival to those placed after starting dialysis. However, post-dialysis graft placement is

(C) 2011 The National Kidney Foundation, Inc. Published by Elsevier Inc. All rights reserved.

Correspondence to: Michael Allon, M.D., Division of Nephrology, PB, Room 226, 1530 Third Avenue S. Birmingham, AL. 35294, Tel (205) 975-9676, Fax (205) 975-8879, mdallon@uab.edu.

Financial Disclosure: The authors declare that they have no relevant financial interests.

Publisher's Disclaimer: This is a PDF file of an unedited manuscript that has been accepted for publication. As a service to our customers we are providing this early version of the manuscript. The manuscript will undergo copyediting, typesetting, and review of the resulting proof before it is published in its final citable form. Please note that during the production process errors may be discovered which could affect the content, and all legal disclaimers that apply to the journal pertain. 
associated with prolonged catheter dependence and frequent bacteremia. Pre-dialysis graft placement may reduce catheter-dependence and bacteremia in selected patients.

Optimal vascular access management continues to be an area of considerable controversy and clinical research efforts (1). Both the National Kidney Foundation's Kidney Disease Quality Outcomes Initiative (KDOQI) guidelines on vascular access (2) and the Fistula First Initiative (http://www.fistulafirst.org) strongly recommend that chronic kidney disease (CKD) patients preferentially receive arteriovenous fistulas, rather than grafts, whenever possible. Nevertheless, there remains a subset of patients whose vasculature is deemed by the surgeon to be more suitable for creation of a graft. In such patients, the KDOQI guidelines suggest placing the graft 3-6 weeks before the anticipated need for dialysis initiation, but it is exceedingly difficult to predict time to dialysis in a given CKD patient (3, 4). The Fistula First Initiative recommends that pre-dialysis patients be sent to the surgeon for "fistula only" evaluation, but does not specify the optimal timing of graft placement in pre-dialysis patients deemed to be unsuitable for a fistula. Postponing graft creation until after initiation of hemodialysis may be problematic, because it exposes the patients to catheter-dependence, with all its attendant complications, including catheter-related bacteremia (5), central vein stenosis (6), and decreased patient survival (7).

A comparison of the outcomes of grafts placed before and after initiation of hemodialysis would be helpful in addressing the uncertainty about the optimal timing of graft creation, as there are no published data regarding this question. If the outcomes of pre-dialysis grafts were comparable to those placed after initiation of dialysis, one could argue for early graft placement in this patient subpopulation. To address this research question, we retrospectively queried a prospective, computerized vascular access database and compared primary graft failure, cumulative graft survival, duration of catheter-dependence, and frequency of catheter-related bacteremia in patients receiving grafts before and after initiation of dialysis.

\section{Methods}

\section{Study population}

The University of Alabama at Birmingham (UAB) has ten clinical nephrologists who provide medical care to a large CKD population. These include $\sim 500$ hemodialysis patients who receive their care at five in-center hemodialysis units in metropolitan Birmingham. Four transplant surgeons performed all the vascular access surgical procedures. Each patient underwent routine preoperative vascular mapping (8), which was used to assist the surgeons in determining the optimal access type (fistula or graft) and location for each patient. New grafts that did not require revision before use were cannulated for dialysis 2-3 weeks after their creation. Patients who did not have a mature fistula or graft at initiation of hemodialysis received a tunneled dialysis catheter inserted in the internal jugular vein. The surgeons revised grafts that failed within one month of their creation. The dialysis catheter was scheduled for removal after successful graft cannulation on 3 consecutive dialysis sessions. When a graft developed suspected critical stenosis or thrombosis $>1$ month after its creation, the patient was referred to an interventional radiologist or nephrologist, who treated the graft with angioplasty or thrombectomy, respectively. Over $95 \%$ of all 
hospitalizations of our dialysis patients occurred at UAB Hospital, allowing for comprehensive follow-up of any complications. Two full-time access coordinators communicated with the physicians and dialysis staff, scheduled all access procedures, and maintained a prospective, computerized database of all vascular access procedures (9).

\section{Data analysis}

We obtained permission from the local Institutional Review Board to review each patient's medical records for research purposes. We retrospectively queried the prospective access database to identify all grafts placed during the 5 -yr period from $1 / 1 / 2004$ to $12 / 31 / 08$. If a patient received more than one graft, only the first graft placed during the study period was included in the analysis. In addition, because graft outcomes may be inferior in patients with a history of failed grafts, we limited our analysis to those patients receiving their first AV graft. The final list included 62 patients whose grafts were placed pre-dialysis and 186 patients whose grafts were placed after they had already initiated hemodialysis. Using the database, we identified the outcomes of all grafts. Primary graft failure was defined as graft failure before the first successful cannulation. Cumulative graft survival in the post-dialysis graft patients was calculated from surgical placement to permanent failure, regardless of the number of interventions required to maintain graft patency. Because we were interested in useful graft survival, we calculated cumulative graft survival in the pre-dialysis graft patients from initiation of dialysis (rather than from the graft creation date). Graft survival was considered to be " 0 days" in patients with a primary graft failure. Patient follow-up was censored at death, kidney transplant, transfer to an outside dialysis unit, or end of study follow-up (12/31/09).

For those patients receiving grafts post-dialysis, we also determined the duration of catheterdependence from graft placement until use of a permanent access. Catheter-related bacteremia was diagnosed in patients with a clinical suspicion, positive blood cultures, and absence of alternative source of infection (10). We calculated the frequency of catheterrelated bacteremia during the period of catheter-dependence for the post-dialysis graft patients. Hospital electronic medical records were used to obtain baseline demographic, clinical, and laboratory characteristics of the study patients.

\section{Statistical analysis}

Baseline characteristics of the two groups were compared using unpaired Student t-tests for continuous variables and Chi-Square tests for categorical variables. Kaplan-Meier survival curves were generated to calculate the primary and cumulative graft survivals, and log rank tests used to compare the differences between the two groups. Univariate Cox proportional hazard models were performed. Hazard ratios and their 95\% confidence intervals (CI) were computed. P values $<0.05$ were considered statistically significant.

\section{Results}

Of the 248 grafts included in our analysis, 62 were placed in pre-dialysis patients and 186 in patients who had already initiated dialysis. The baseline demographic and clinical characteristics of the two groups are summarized in Table 1 . The majority of the patients 
were black, reflecting the demographic distribution in our dialysis population. Almost twothirds of the patients were female. About $90 \%$ of the patients had hypertension, over half had diabetes, and a substantial proportion had vascular disease. The pre-dialysis patients were older than those receiving a graft post-dialysis. Otherwise, the two study groups did not differ significantly in their demographic features or co-morbidities. Not surprisingly, over half of the post-dialysis patients had had at least one previous fistula, and $17 \%$ had 2 or more previous fistulas. Even among the pre-dialysis patients, nearly one-third had had at least 1 prior access, and $10 \%$ had had 2 or more prior fistulas. Anticoagulation was prescribed in $6 \%$ of the post-dialysis group, but none of the pre-dialysis group. The study graft was placed in the thigh in $11 \%$ of the post-dialysis patients, but none of the pre-dialysis patients. Among the post-dialysis group, $74 \%$ of the patients initiated hemodialysis with a catheter, and about two-thirds received their first graft within a year of initiating hemodialysis.

The mean eGFR at the time of surgery was $13 \pm 4 \mathrm{ml} / \mathrm{min} / 1.73 \mathrm{~m}^{2}$ in the patients receiving their grafts pre-dialysis. Among the 62 patients with pre-dialysis grafts, 1 died pre-dialysis, 2 received a kidney transplant before starting dialysis, 2 did not initiate dialysis by the end of the study follow-up, and 7 were lost to follow-up before initiating dialysis. Of the remaining 50 patients whose grafts were placed pre-dialysis, 10 (or 20\%) had a primary graft failure before starting dialysis, and 40 initiated dialysis with the graft (Table 2). The median time from graft placement to first cannulation in the pre-dialysis group was 59 days, with a range of 10 to 1008 days. Eight of the 40 patients (20\%) who initiated dialysis with a graft had had their surgery $>6$ months prior to initiation of dialysis. Among 186 patients receiving graft surgery post-dialysis, 45 (or $24 \%$ ) experienced a primary graft failure (Table 2 ). Thus, the frequency of primary failure was similar in the pre-dialysis and post-dialysis grafts $(\mathrm{p}=0.5)$.

The cumulative graft survival was similar for the 2 groups, with a median survival of 365 days for pre-dialysis grafts and 414 days for post-dialysis grafts $(\mathrm{p}=0.3)$ (Table 2, Figure 1). The hazard ratio for graft failure in the pre-dialysis group was 1.22 (95\% CI, 0.81-1.98). Because the pre-dialysis and post-dialysis groups differed in terms of graft location and frequency of a previous fistula (Table 1), we repeated the comparison of the survival curves, after statistical adjustment for these 2 factors. In the adjusted analysis, the hazard ratio for cumulative graft failure in the pre-dialysis patients was 1.06 (95\% CI, 0.70-1.59; $\mathrm{p}=0.8$ ). Graft infections requiring surgical intervention occurred in 2 of $50(4 \%)$ pre-dialysis graft patients who intiated hemodialysis and 8 of $250(3.2 \%)$ post-dialysis grafts $(\mathrm{p}=0.8)$.

Among the 186 post-dialysis graft patients, the median duration of catheter dependence from graft surgery was 48 days. During this time, these patients experienced a mean of 0.63 (95\% CI, 0.48 to 0.79 ) episodes of catheter-related bacteremia (Table 2). In contrast, of the 50 predialysis graft patients, 40 started dialysis with their study graft and an additional 3 patients with primary failure of their graft initiated dialysis with a subsequent permanent access. In other words, 43 patients (86\%) of this group had no catheter-dependence at initiation of dialysis. The remaining 7 pre-dialysis patients with primary graft failure were catheter dependent for a median of 117 days, during which they had a mean of 0.57 episodes of catheter-related bacteremia. 
Of the 40 pre-dialysis graft patients who initiated hemodialysis with a functioning graft, 22 experienced subsequent graft failure. The next access in this patient subgroup was a fistula in 7 patients, graft in 8 , and Tenckhoff in 1, whereas 6 patients remained catheter-dependent during study follow-up.

\section{Discussion}

As a result of the KDOQI and Fistula First guidelines, there has been a dramatic shift from grafts to fistulas in hemodialysis patients over the past few years. This shift has also occurred at our institution, such that the majority of post-dialysis study patients had received one or more fistulas before placement of the study graft (Table 1). Nonetheless, there is clearly a subset of CKD patients in whom a fistula has a high likelihood of non-maturation. These include patients with a prior failed fistula, older patients with a limited life expectancy, and those with substantial vascular co-morbidity (11-13). Placement of a graft may be a more suitable alternative than a fistula in this subset. However, as a result of rigid vascular access guidelines, there has been a progressive reluctance by access surgeons over the past few years to place grafts in CKD patients. This reticence has been particularly pronounced in pre-dialysis patients who are deemed unsuitable candidates for fistula creation. When a pre-dialysis patient is referred to the surgeon for a "fistula only" evaluation (as recommended by the Fistula First Initiative), the surgeon may defer graft surgery until after the patient has initiated maintenance dialysis if the patient is a poor candidate for a fistula. Even to adhere to the KDOQI guidelines, the surgeon would have to reliably predict the timing of initiation of dialysis. Such predictions are notoriously difficult $(3,4)$. If the surgeon's estimate were incorrect, the patient would initiate dialysis with a catheter.

Our study demonstrates that the outcomes of arteriovenous grafts are similar between grafts placed pre-dialysis and those created after initiation of maintenance dialysis. There were no significant differences in terms of multiple access outcomes, including primary graft failure rate, cumulative graft survival, or frequency of graft infection. These results provide reassurance that pre-dialysis graft placement is a reasonable strategy in selected patients, even when there are long delays before the need for dialysis initiation. A more liberal policy in this regard would help reduce the proportion of patients needing to start dialysis with a catheter, which is currently at $80 \%$ in the U.S. (14), and was $74 \%$ in the current study. Eighty-six percent of our pre-dialysis patients initiated hemodialysis with a permanent access, thereby obviating the need for a catheter. In contrast, the patients receiving graft surgery after dialysis initiation were catheter-dependent for a mean of 4 months. This delay is consistent with results from a recent national hemodialysis database, which reported that among patients initiating hemodialysis with a catheter and an immature graft, $46.5 \%$ were catheter-dependent at 90 days (15). The prolonged catheter dependence of our post-dialysis graft patients resulted in a high frequency of catheter-related bacteremia. Although not quantified, it is likely that a subset of these patients developed central vein stenosis, which might adversely affect the outcome of their future vascular accesses (6).

The primary graft failure rate observed in the current study is in line with the 15 to $23 \%$ range reported in several previous investigations (16-19). Likewise, the cumulative graft survival and frequency of graft infections are in agreement with prior publications. One 
might argue that the higher frequency of thigh grafts creates a bias against graft outcomes in the post-dialysis group. However, large comparative studies have reported that thigh graft survival is comparable, or even better than that obtained with upper extremity grafts (20, 21). Moreover, cumulative graft survival was similar between both groups even after adjustment for the differences in access location.

There has been growing concern in the nephrology community regarding the high proportion of patients initiating hemodialysis with a catheter (14). These concerns have led to recommendations for aggressive strategies to reduce catheter use among incident and prevalent hemodialysis patients (22-26). The current study suggests that placement of AV grafts in selected patients before initiation of hemodialysis may be a valuable cathetersparing strategy. Furthermore, it raises the intriguing possibility that among pre-dialysis patients who are at high risk for fistula non-maturation, placement of a graft may be a viable strategy. A randomized clinical trial comparing fistula and graft placement in such high-risk pre-dialysis patients is warranted to provide definitive answers to this important clinical question (27).

The present study has some limitations. First, the data analysis was performed retrospectively. However, all the access outcomes were recorded prospectively in a computerized database by dedicated access coordinators, so the data are likely to be comprehensive and accurate. Second, the results represent outcomes from a single large dialysis center, and may not generalize to all dialysis centers.

In conclusion, our results show that grafts placed prior to initiation of hemodialysis offer a similar lifespan, as compared with those placed after dialysis has been started, while sparing the need for catheter use with its attendant complications. In selected pre-dialysis patients who are deemed unsuitable for creation of a fistula, the graft should be placed expeditiously, without waiting for dialysis initiation.

\section{Acknowledgments}

Support: None.

\section{References}

1. Allon M. Current management of vascular access. Clin J Am Soc Nephrol. 2007; 2:786-800. [PubMed: 17699495]

2. National Kidney Foundation. KDOQI clinical practice guidelines and clinical practice recommendations for vascular access 2006. Am J Kidney Dis. 2006; 48 (suppl 1):S176-S322. [PubMed: 16813989]

3. O'Hare AM, Bertenthal D, Walter LC, Garg AX, et al. When to refer patients with chronic kidney disease for vascular access surgery: should age be a consideration? Kidney Int. 2007; 71:555-561. [PubMed: 17245396]

4. Cooper BA, Branley P, Bulfone L, Collins JF, et al. A randomized, controlled trial of early versus late initiation of dialysis. N Engl J Med. 363:609-619. [PubMed: 20581422]

5. Allon M. Dialysis catheter-related bacteremia: Treatment and prophylaxis. Am J Kidney Dis. 2004; 44:779-791. [PubMed: 15492943]

6. Agarwal AK, Patel BM, Haddad NJ. Central vein stenosis: A nephrologist's perspective. Semin Dial. 2007; 20:53-62. [PubMed: 17244123] 
7. Allon M, Daugirdas JT, Depner TA, Greene T, et al. Effect of change in vascular access on patient mortality in hemodialysis patients. Am J Kidney Dis. 2006; 47:469-477. [PubMed: 16490626]

8. Robbin ML, Gallichio ML, Deierhoi MH, Young CJ, et al. US vascular mapping before hemodialysis access placement. Radiology. 2000; 217:83-88. [PubMed: 11012427]

9. Allon M, Bailey R, Ballard R, Deierhoi MH, et al. A multidisciplinary approach to hemodialysis access: prospective evaluation. Kidney Int. 1998; 53:473-479. [PubMed: 9461109]

10. Allon M. Treatment guidelines for dialysis catheter-related bacteremia: An update. Am J Kidney Dis. 2009; 54:13-17. [PubMed: 19559337]

11. Lee T, Barker J, Allon M. Comparison of survival of upper arm arteriovenous fistulas and grafts after failed forearm fistulas. J Am Soc Nephrol. 2007; 18:1936-1941. [PubMed: 17475812]

12. Lok CE, Allon M, Moist LM, Oliver MJ, et al. REDUCE FTM I (Risk equation determining unsuccessful cannulation events and failure to maturation in arteriovenous fistulas). J Am Soc Nephrol. 2006; 17:3204-3212. [PubMed: 16988062]

13. Richardson AI, Leake A, Schmieder GC, Biuckians A, et al. Should fistulas really be first in the elderly patient? J Vasc Access. 2009; 10:199-202. [PubMed: 19670174]

14. Collins AJ, Foley RN, Gilbertson DT, Chen SC. The state of chronic kidney disease, ESRD, and morbidity and mortality in the first year of dialysis. Clin J Am Soc Nephrol. 2009; 4 (Suppl 1):S511. [PubMed: 19996006]

15. Lacson, EK.; Wang, W.; Lazarus, M.; Hakim, R. Arteriovenous vascular access maturation and failure rates in the 1st 90 days. Proceedings of the American Society of Nephrology meeting; San Diego. October 27-November 1, 2009; 2009. F-FC296

16. Allon M, Lockhart ME, Lilly RZ, Gallichio MH, et al. Effect of preoperative monographic mapping on vascular access outcomes in hemodialysis patients. Kidney Int. 2001; 60:2013-2020. [PubMed: 11703621]

17. Dixon BS, Novak L, Fangman J. Hemodialysis vascular access survival: upper-arm native arteriovenous fistula. Am J Kidney Dis. 2002; 39:92-101. [PubMed: 11774107]

18. Maya ID, O’Neal JC, Young CJ, Barker-Finkel J, et al. Outcomes of brachiocephalic fistulas, transposed brachiobasilic fistulas, and upper arm grafts. Clin J Am Soc Nephrol. 2009; 4:86-92. [PubMed: 18945990]

19. Oliver MJ, McCann RL, Indridason OS, Butterly DW, et al. Comparison of transposed brachiobasilic fistulas to upper arm grafts and brachiocephalic fistulas. Kidney Int. 2001; 60:15321539. [PubMed: 11576369]

20. Miller CD, Robbin ML, Barker J, Allon M. Comparison of arteriovenous grafts in the thigh and upper extremities in hemodialysis patients. J Am Soc Nephrol. 2003; 14:2942-2947. [PubMed: 14569105]

21. Ram SJ, Sachdeva BA, Caldito GC, Zibari GB, et al. Thigh grafts contribute significantly to patients' time on dialysis. Clin J Am Soc Nephrol. 5:1229-1234. [PubMed: 20413439]

22. Kulawik D, Sands JJ, Mayo K, Fenderson M, et al. Focused vascular access education to reduce the use of chronic tunneled hemodialysis catheters: results of a network quality improvement initiative. Semin Dial. 2009; 22:692-697. [PubMed: 20017841]

23. Polkinghorne KR, Seneviratne M, Kerr PG. Effect of a vascular access nurse coordinator to reduce central venous catheter use in incident hemodialysis patients: a quality improvement report. Am $\mathrm{J}$ Kidney Dis. 2009; 53:99-106. [PubMed: 18805614]

24. Allon M. Fistula First: Recent progress and ongoing challenges. Am J Kidney Dis. In Press.

25. Lacson E, Lazarus JM, Himmelfarb J, Ikizler TA, et al. Balancing fistula first with catheters last. Am J Kidney Dis. 2007; 50:379-395. [PubMed: 17720517]

26. Hakim RM, Himmelfarb J. Hemodialysis access failure: a call to action - revisited. Kidney Int. 2009; 76:1040-1048. [PubMed: 19710629]

27. Allon M, Lok CE. Dialysis fistula or graft: The role for randomized clinical trials. Clin J Am Soc Nephrol. 2010; 5:2348-2354. [PubMed: 21030576] 


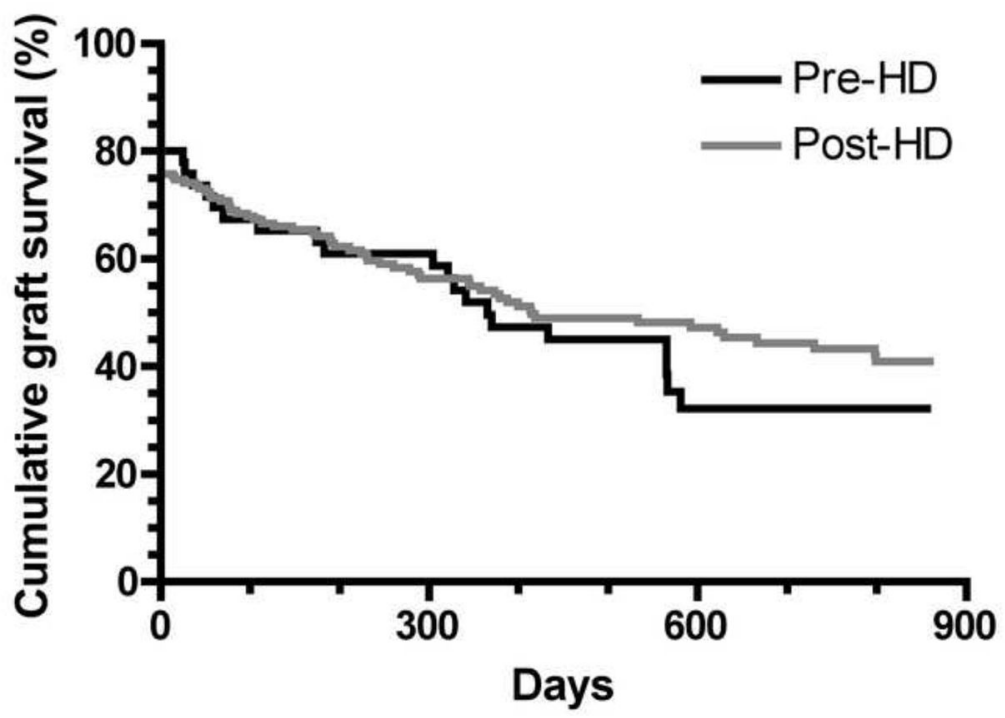

Figure 1.

Cumulative survival of grafts placed pre-dialysis (black line) and after initiation of dialysis (gray line). $\mathrm{P}=0.3$. Analysis is restricted to patient receiving their first AV graft. Graft survival in pre-dialysis patients was calculated from initiation of hemodialysis. Graft survival was considered to be " 0 days" in patients with a primary graft failure. 
Table 1

Demographic and clinical features of the study population

\begin{tabular}{|c|c|c|c|}
\hline & Pre-dialysis & Post-dialysis & p-value \\
\hline$N p t s$ & 62 & 186 & \\
\hline Age, $y r$ & $58 \pm 17$ & $54 \pm 15$ & 0.05 \\
\hline Sex, male $(N, \%)$ & $22(35 \%)$ & $77(41 \%)$ & 0.4 \\
\hline Race, $\operatorname{black}(N, \%)$ & $52(84 \%)$ & $159(85 \%)$ & 0.6 \\
\hline Diabetes $(N, \%)$ & $32(52 \%)$ & $101(54 \%)$ & 0.7 \\
\hline Hypertension $(N, \%)$ & $56(90 \%)$ & $167(90 \%)$ & 0.9 \\
\hline Coronary artery disease $(N, \%)$ & $15(24 \%)$ & $49(26 \%)$ & 0.7 \\
\hline Peripheral vascular disease $(N, \%)$ & $6(10 \%)$ & $27(14 \%)$ & 0.3 \\
\hline Cerebrovascular disease $(N, \%)$ & $9(14 \%)$ & $24(13 \%)$ & 0.8 \\
\hline Graft location & & & 0.006 \\
\hline Forearm & $23(37 \%)$ & $37(20 \%)$ & \\
\hline Upper arm & $39(63 \%)$ & $128(69 \%)$ & \\
\hline Thigh & $0(0 \%)$ & $21(11 \%)$ & \\
\hline$N$ of previous fistulas & & & 0.002 \\
\hline 0 & $44(71 \%)$ & $90(48 \%)$ & \\
\hline 1 & $12(19 \%)$ & $64(34 \%)$ & \\
\hline 2 & $5(8 \%)$ & $22(12 \%)$ & \\
\hline 3 & $1(2 \%)$ & $10(5 \%)$ & \\
\hline Year graft placed & & & 0.08 \\
\hline 2004 & $14(22 \%)$ & $19(10 \%)$ & \\
\hline 2005 & $15(24 \%)$ & $37(20 \%)$ & \\
\hline 2006 & $11(18 \%)$ & $47(25 \%)$ & \\
\hline 2007 & $10(16 \%)$ & $37(20 \%)$ & \\
\hline 2008 & $11(18 \%)$ & $46(25 \%)$ & \\
\hline Anticoagulation & $0(0 \%)$ & $12(6 \%)$ & 0.04 \\
\hline \multicolumn{4}{|l|}{$H D$ vintage $(N, \%)$} \\
\hline$<1 y r$ & N/A & $129(69 \%)$ & \\
\hline $1-2 y r$ & N/A & $29(16 \%)$ & \\
\hline$>2 y r$ & N/A & $28(15 \%)$ & \\
\hline
\end{tabular}

Values shown as number, mean $+/-\mathrm{SD}$, or no. (\%).

Abbreviations: HD, hemodialysis 


\section{Table 2}

\section{Clinical outcomes of grafts}

\begin{tabular}{|l|c|c|c|}
\hline & Pre-dialysis & Post-dialysis & p-value \\
\hline$N$ pts & $50^{*}$ & 186 & \\
\hline Primary failures, $N(\%)$ & $10(20 \%)$ & $45(24 \%)$ & 0.5 \\
\hline Graft infection, $N(\%)$ & $2(4.0 \%)$ & $8(3.2 \%)$ & 0.8 \\
\hline Median Cumulative graft survival (days) & 365 & 414 & 0.3 \\
\hline Median Catheter-dependence after graft creation (days) & N/A & 48 & \\
\hline Mean CRBs during catheter- dependence & N/A & $0.63(0.48-0.79)^{* *}$ & \\
\hline
\end{tabular}

Excludes 12 patients who never initiated dialysis after graft surgery.

** $95 \%$ CI shown in parentheses

$\mathrm{CRB}$, catheter-related bacteremia 